\title{
Ion-Enhanced Adhesion of Thin Gold Films
}

\author{
PhilipJ. Martin \\ CSIRO Division of Applied Physics, Sydney, Australia 2070
}

\begin{abstract}
The adbesion of gold films to many surfaces of technological importance, such as glass and silicon, bas in recent years been substantially improved by the use of ion bombardment. Ions may also play an important role in the film deposition process, depending on the metbod employed. Low-energy oxygen bombardment during deposition gives rise to a strong bonding effect, wbilst mediumenergy inert-gas ion bombardment can promote interfacial mixing. High-energy ion and electron post-bombardment of gold films give rise to another bonding mechanism which is thought to result in electronic interactions at the film-substrate interface.
\end{abstract}

The purpose of this article is to review the initial growth processes of gold films on surfaces, and the influence of ion bombardment both during and after deposition. A brief description of the methods of assessing adhesion is given first, followed by a summary of the physical vapour deposition (PVD) processes used in gold deposition, since the method employed can strongly influence the final film adhesion.

Thin films play a vital role in many high technology areas since they can be used to modify the properties of the surfaces on which they are deposited. These modifications include changes to the optical, electrical, magnetic, wear-resistant and corrosion-resistant properties.

Most of the techniques used to deposit gold films are physical vapour deposition methods, (PVD), carried out in a vacuum environment. The properties of the deposited films are influenced to varying degrees by the parameters used in the deposition process, such as the deposition rate, pressure in the vacuum vessel, temperature of the substrate etc.

Since the film must adhere strongly to the substrate in order to perform satisfactorily, care must be taken to clean the substrate surface prior to coating. Preparation of high quality films is in general best achieved when a final in situ surface cleaning step is performed in the vacuum deposition system. The various types of PVD techniques offer varying degrees of final substrate surface preparation.

In recent years it has been found that the adhesion of gold films can be increased substantially by low-energy ion bombardment during deposition and also by post-bombardment of a deposited film with high-energy particle beams.

\section{Adhesion of Thin Films}

The measurement of thin film adhesion is at best a difficult task and, for some systems, close to impossible. There exists a number of techniques which are frequently employed and only a brief description is given here.

The simplest test is the 'tape test' (1), where a piece of adhesive tape is pressed onto the film. The film is considered to have passed the test if it is not removed when the tape is peeled away. The pull method relies upon the use of a pin or stud which is cemented by a suitable adhesive to the film surface. The force required to remove the pin is then a measure of the adhesion (2). Problems exist with the type of cement used and its influence on the film-substrate interface in the case of porous layers. A related test is the topple test (3). Here a rod is cemented to the film surface and a lateral (instead of normal) force is applied. In this case the stress distribution is more complex than the direct pull method.

The scratch test is frequently used for assessing adhesion (4). Here a stylus with a well-defined radius is drawn across the surface. The load on the stylus necessary to remove the film from the substrate is a measure of the adhesion. The test is difficult to analyse because of the complexity of the system, but comparative measurements of a given film-substrate combination appear to give consistent results. The scratch test has been refined to a high degree and several automatic testing devices are commercially available.

In the case of film deposits which are too small for other tests, the cotton bud test is frequently used. The film is simply rubbed with a Q-tip cotton bud, and its resistance to this abrasive action is a qualitative measurement of the adhesion. 


\section{PVD Processes for Gold Deposition}

Generally PVD processes for gold deposition may be divided into two categories, those based on evaporation and those based on sputtering. The type of process employed depends upon the particular application required, i.e. area to be coated, uniformity of coating, sensitivity of the substrate to thermal radiation etc.

Evaporation is the most commonly used technique. Gold is placed in a tungsten or molybdenum boat and heated to the point of evaporation. The vapour condenses on the substrate which is mounted directly above the source. This method of deposition is economical and available in most thin-film laboratories as a simple method of metallisation. Film thickness is either controlled by measurements of optical transmittance or reflectance or by a quartz crystal microbalance. Where greater control over the deposition process is required, electron-beam evaporation is used. In both cases the energy of the evaporated atoms is only a small fraction of an electron volt.

In electron-beam evaporation some ionisation of the evaporant occurs through interaction with the electron beam (5). Although the ionised fraction is small $(0,01$ per cent), thin film nucleation and growth can be modified if these ions are accelerated to the substrate during film deposition.

\section{Ion-Assisted Deposition (IAD)}

Considerable control over the substrate cleaning stage, initial nucleation stage and film structure can be achieved if the growing film and substrate are irradiated with a beam of energetic particles. The technique was first tested on optical thin films by Heitmann (6), who used a discharge tube to create oxygen ions during thermal evaporation of materials.

In recent years the Kaufman ion source (7) (shown in Figure 1), originally designed as a thruster for space vehicle propulsion, has been introduced into thin film deposition technology. The Kaufman source can provide high fluxes of ions over large areas with a well-defined energy that is variable from approximately $30 \mathrm{eV}$ to a few $\mathrm{keV}$. The gun can produce beams of both reactive and inert gas ions, and mass analysis shows that the beams contain a high proportion of molecular species. In the case of reactive ion beams such as hydrogen, oxygen, and nitrogen, the dimer to monomer ratio (e.g. $\mathrm{O}_{2}^{+} / \mathrm{O}^{+}$) is approximately 3.5. Energy analysis of the beam reveals an energy spread of $10 \mathrm{eV}$ or less at $500 \mathrm{eV}$. This is to be compared with the wide distribution in ion energies of 1 to $100 \mathrm{eV}$ or more present in a discharge-type ion source.

The ion current densities obtainable may be as high as 200 $\mathrm{A} / \mathrm{m}^{2}$ for some source designs. The size of the beam is determined by the source geometry and commercial sources of 150 $\mathrm{mm}$ diameter are available. The lifetime of the cathode (usually a tungsten hairpin filament) is restricted to only a few hours when operated in oxygen. The lifetime can be improved by the

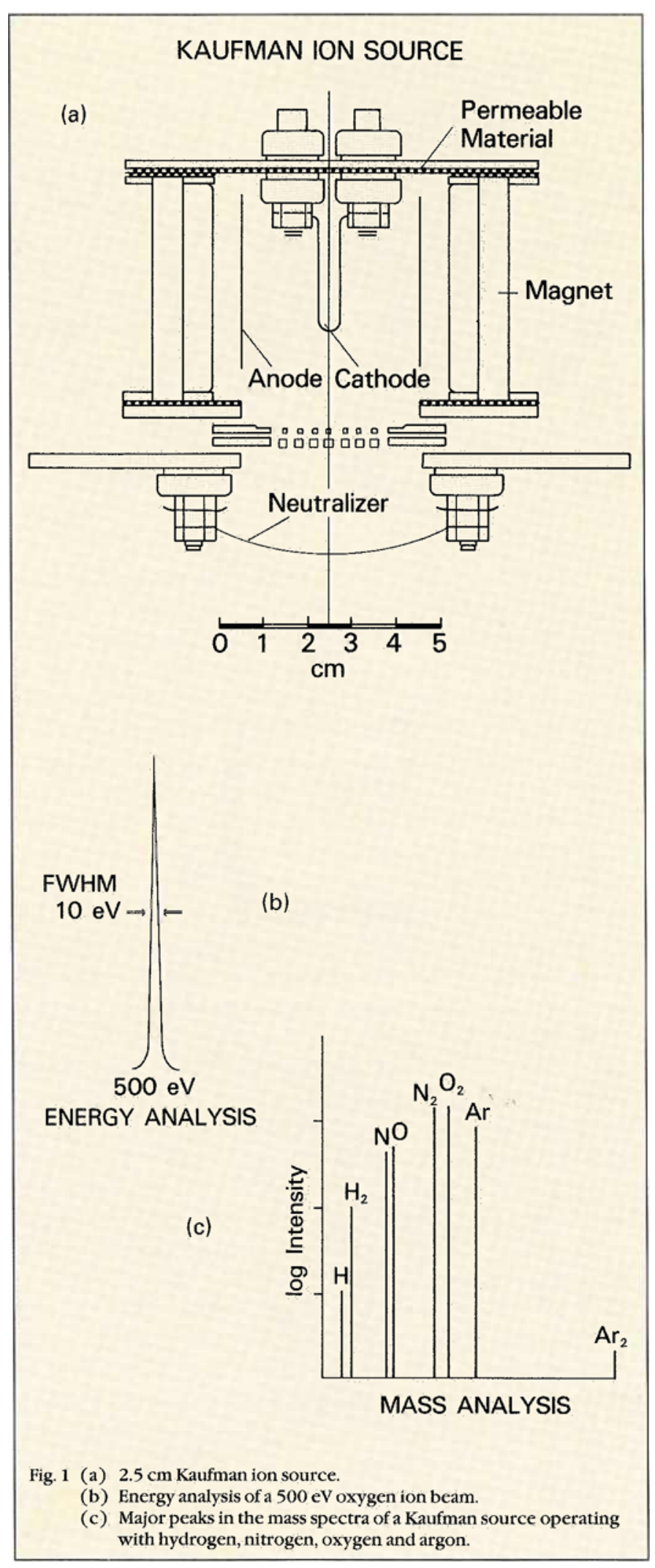



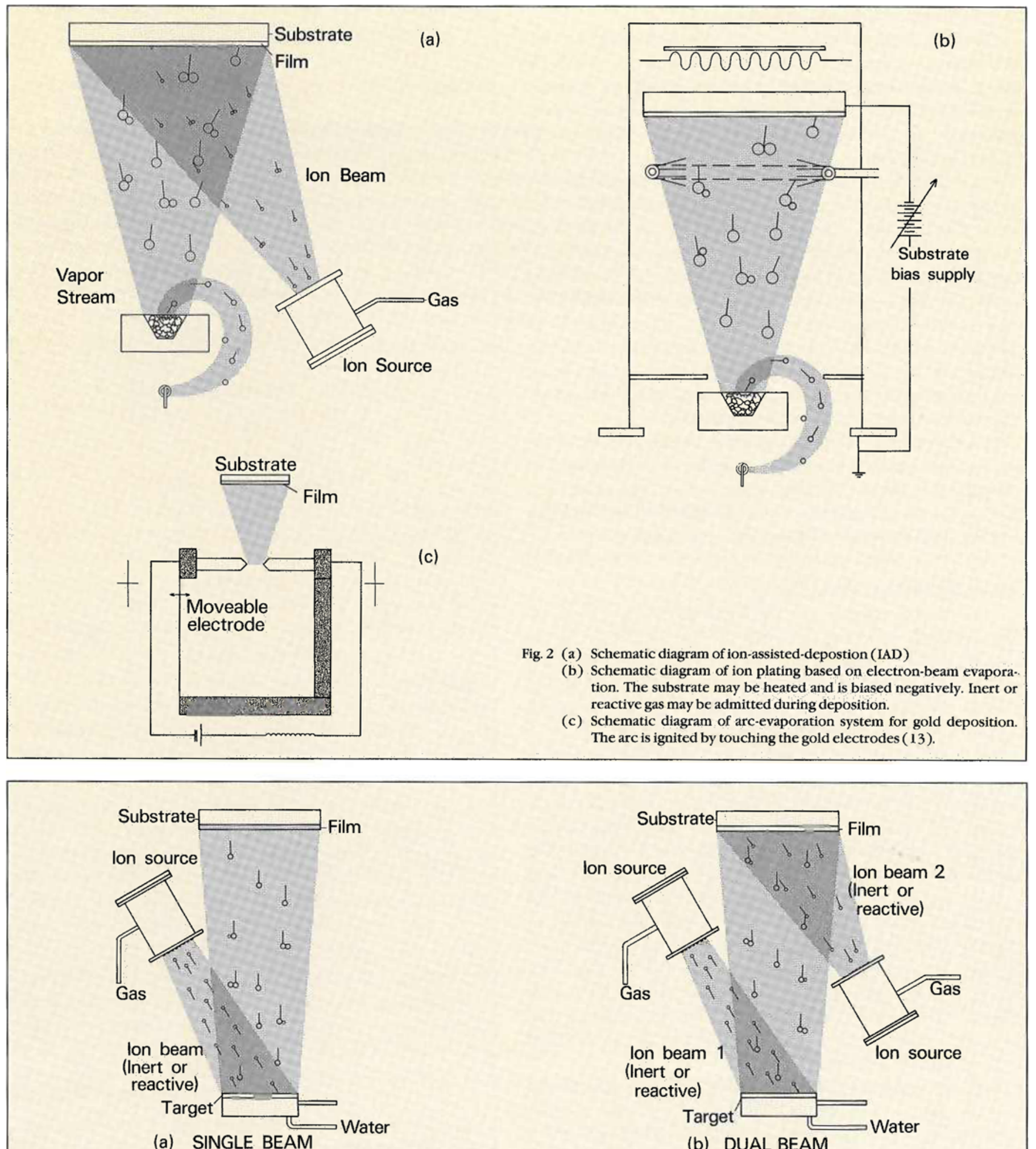

Fig. 3 (a) Single beam sputtering (b) Dual beam sputtering. 
use of thorium oxide coated irridium cathodes.

A conventional thermal or electron-beam evaporation system is readily converted to IAD by mounting the Kaufman source in the chamber and providing some means of measuring the ion flux (Figure $2 a$ ). There have been many reports in the literature on the influence of IAD on thin film deposition and substantial improvements in optical properties observed (see reference 7 for a review of optical materials)

\section{Ion Plating}

Ion plating was first discussed in detail by Mattox (8) who combined thermal evaporation with a glow discharge (Figure $2 \mathrm{~b})$. In this technique, ions are produced by evaporating material in the region of a $2-5 \mathrm{keV}$ inert gas discharge. A fraction of the ionised atoms is then accelerated across the dark space to the cathode (substrate). The ions experience energy loss through collisions with other atoms and through charge exchange processes. It has been estimated that the substrate is bombarded by 20 energetic neutrals for each ion leaving the edge of the dark space (9). The average ion energy is approximately $30 \mathrm{eV}$ and the average neutral particle energy $135 \mathrm{eV}$. The ion flux is sufficient to clean the substrate and influence film growth processes. The technique is able to coat all sides of the substrate due to the high degree of scattering of evaporated atoms by the high pressure of the inert gas. Ion plating is also frequently used for synthesising oxides, nitrides and carbides (10) by introducing a suitable reactive gas into the vacuum system.

\section{Arc Evaporation}

Arc-evaporation techniques (11) have been used extensively in the deposition of hard wear-resistant coatings for industrial applications but are now being refined to deposit high quality films for a wide range of applications. The principle advantage of an electric-arc-based thin film deposition process is that a significant percentage of the evaporant is ionised. Multiply charged species as high as the fourth charge state have been observed for some materials. The basic arrangement for arc evaporation is shown in Figure $2 \mathrm{c}$. The electrodes are brought together to strike the arc. A cathode spot is then ignited which moves in a random fashion across the surface of the cathode. In the region of the cathode spot, electron emission, vaporisation and ionisation of the cathode metal vapour occur simultaneously such that the spot becomes self-sustaining. The spot or spots move at high velocity and are a source of high currentdensity $10^{5}-10^{8} \mathrm{~A} / \mathrm{cm}^{2}(12)$. The temperature of the cathode spot has been estimated for a range of cathode materials (13), the value for gold being $3620 \mathrm{~K}$. The cathode spot produces a highspeed plasma stream comprising neutral atoms, ions, electrons and liquid droplets (macro-particles). The energy of the emitted ions is typically $40 \mathrm{eV}$ per charge state (14) and can be increased by negatively biasing the substrate to accelerate the depositing ions. The principal disadvantage with arc-based technology is the presence of the macro-particles. For gold cathodes the macro-particle sizes range up to 6 microns in diameter and 10 per cent of the emitted volume is comprised of particles of 3-5 microns (15). The macro-particles impact the substrate along with neutral atoms and gold ions and can lead to film porosity. Various schemes have been tried to reduce or totally eliminate the macro-particle contribution with some success (16). The arc process has a very high deposition rate, approaching microns per minute for some material. Some reports also indicate that epitaxial film growth for gold on $\mathrm{NaCl}$ is possible at reduced epitaxial temperatures (17), and suggestions have been made that the high degree of clusters in the beam are responsible. It is, however, more likely that the ion flux is largely responsible for any modifications of film growth during deposition.

\section{Sputter Deposition Techniques}

When an energetic ion (energy greater than $20-40 \mathrm{eV}$ ) impacts a solid surface a collision cascade is created in the outermost atomic layers. Some of the energy of the cascade is eventually transferred to the surface atoms which, if sufficient, will cause them to be ejected into the vacuum. This process, termed sputtering, is present during any interaction of a suitably energetic ion with a solid surface and can be used to deposit films by collecting the sputtered material on a substrate.

There are many forms of sputter deposition techniques and a complete survey is outside the scope of this brief review. The basic sputter deposition process is illustrated by single and dual-ion-beam sputtering shown in Figure 3. Here the Kaufman ion source is directed onto a gold target. A beam of ions, typically $1 \mathrm{keV} \mathrm{Ar}^{+}$, sputter gold atoms from the target and a film is deposited on the substrate. The rate of deposition is ultimately determined by the number of gold atoms ejected per incident ion (sputtering yield). The sputtering yield for gold is determined by the mass, energy and angle of incidence of the ions. For $1 \mathrm{keV} \mathrm{Ar}^{+}$on gold the sputtering yield is $3-4$ atoms per ion (18). If a second ion gun is available to bombard the substrate before or during the film growth, the technique is termed dual-beam-sputtering (DBS)

The advantage of sputter-based systems is that the energy of the depositing atoms is higher than that produced by evaporation. Sputtered particles typically have energies of $5-10 \mathrm{eV}$, which is sufficient to promote denser film growth than is possible by thermal evaporation. Loosely bonded atoms on the substrate (contaminants or gold) are themselves sputtered by the second ion gun prior to or during deposition. This can result in greatly improved adhesion for some systems. The adhesion of sputter-deposited gold on glass is greater than that of evaporated films (19). 


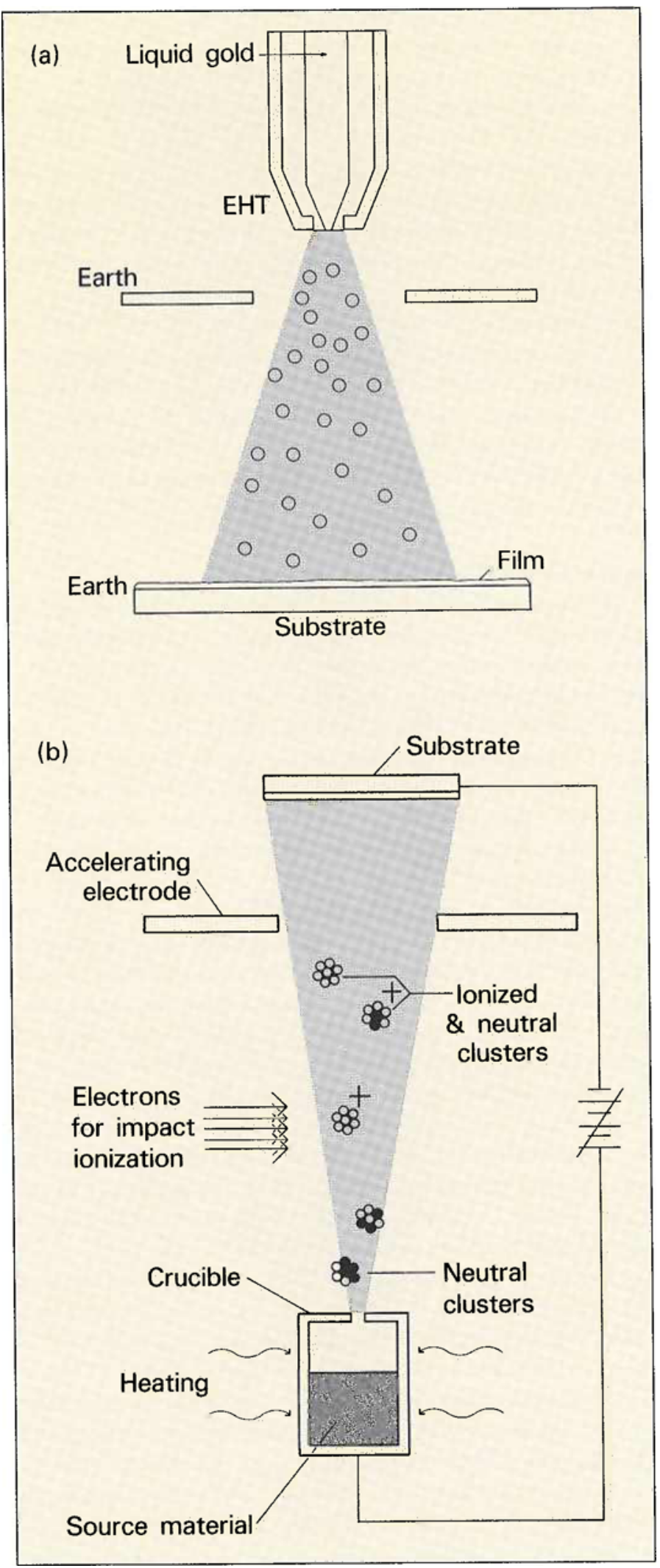

\section{Ion Beam Deposition}

The ideal deposition technique is one which has a variable deposition energy of the gold atoms where sputter-cleaning of the substrate is possible before the energy is reduced to a level at which a net deposition occurs. Arc evaporation is close to this ideal but has some drawbacks.

Ion beam deposition (IBD) is somewhat closer in which the depositing atoms are ionised, accelerated and then deposited. The liquid metal ion source (20), recently introduced as a high brightness source of metal ion beams, has been demonstrated to produce excellent gold deposits. The source is shown in Figure 4a. The process uses a field emission spray system composed of mixed beams of molten droplets and metal ions produced by applying a high electric field to a nozzle containing molten gold in a vacuum. The spray is then directed onto a substrate. The ions travel at high velocities $\left(10^{5} \mathrm{~m} / \mathrm{s}\right)$ and can sputter-clean the substrate to provide good adhesion for the molten droplets. Coating rates of 1 micron per minute over a few square centimetres have been reported.

Another technique which uses an ion beam type technology is ionised cluster beam deposition (ICB), shown in Figure 4b. Vaporised metal clusters are formed by adiabatic expansion through a nozzle leading to the deposition chamber. The clusters of 500-1000 atoms are ionised by electron bombardment in an electrode assembly mounted over the crucible and accelerated towards the substrate. The cluster breaks up on impact by an amount which depends on the angle of incidence and accelerating voltage. If complete dissociation occurs, each atom has an average energy $E=e V_{a} / N$, where $e$ is the electric charge, $V_{a}$ the acceleration voltage and $N$ the number of atoms in the cluster.

Typical values for $E$ are $0.1-10 \mathrm{eV}$. Recent computer simulations, however, show that complete dissociation does not occur and that the cluster may simply stack on the substrate surface with some relaxation to reduce inter-cluster voids (22). An example of such a simulation is shown in Figure 5.

(Continued on page 108)

Fig. 4 (a) Gold deposition by field emission from a liquid metal ion source $(20)$.

(b) Ionised cluster beam deposition system ICBD (21). 

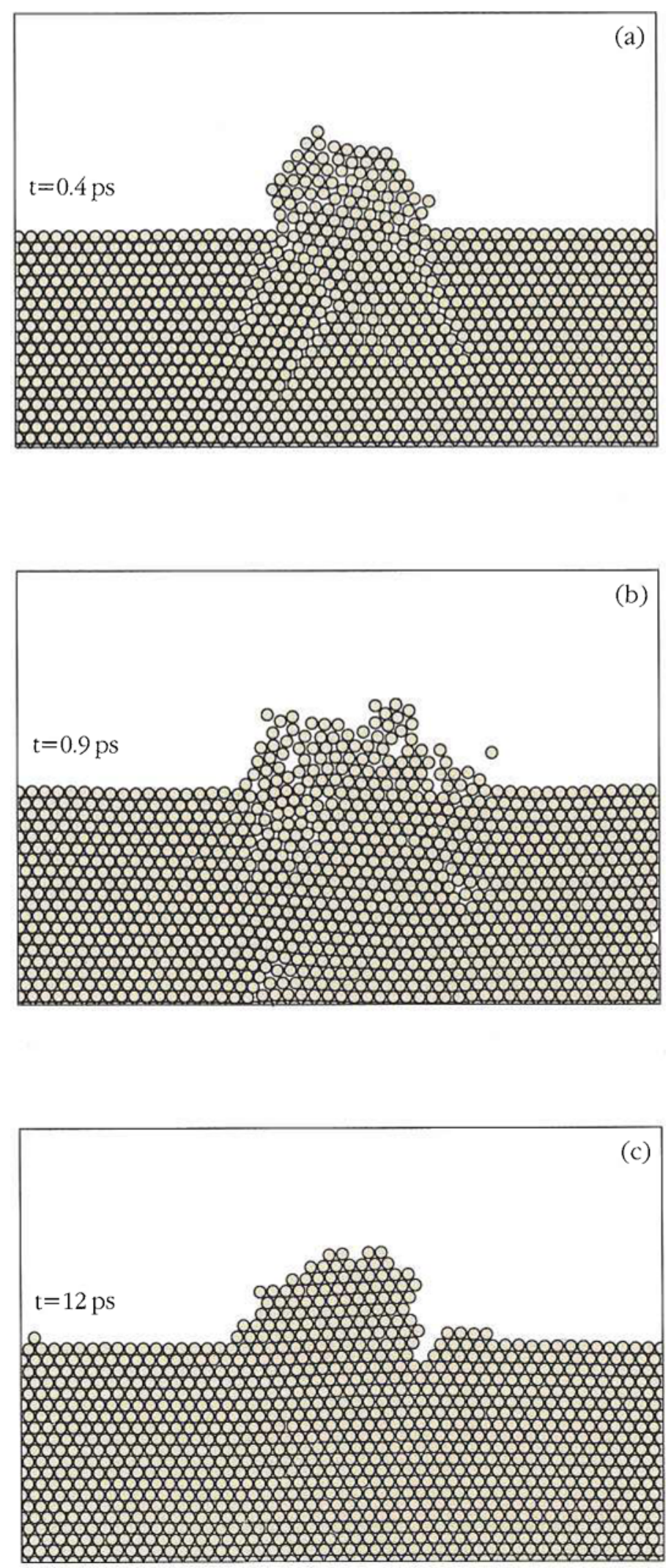

GoldBull, 1986, 19, (4)
Fig. 5 Computer simulation of film growth by ICBD (22).

(a) -(c) Impact of a single cluster on the substrate after $2 \mathrm{kEv}$ acceleration at $0.4,0.9$, and 12 ps after impact.

(d) Simulation of multiple cluster film growth. (b)

c)

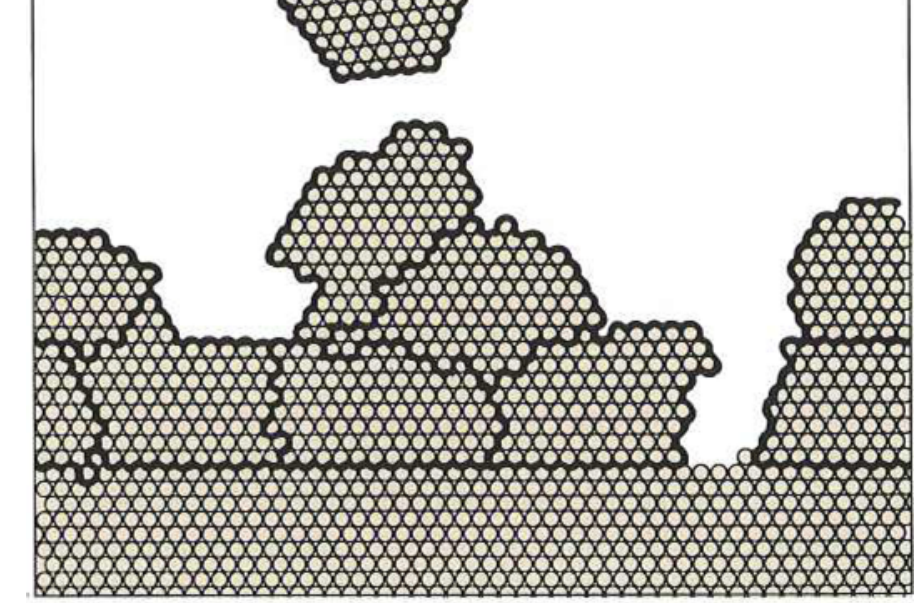




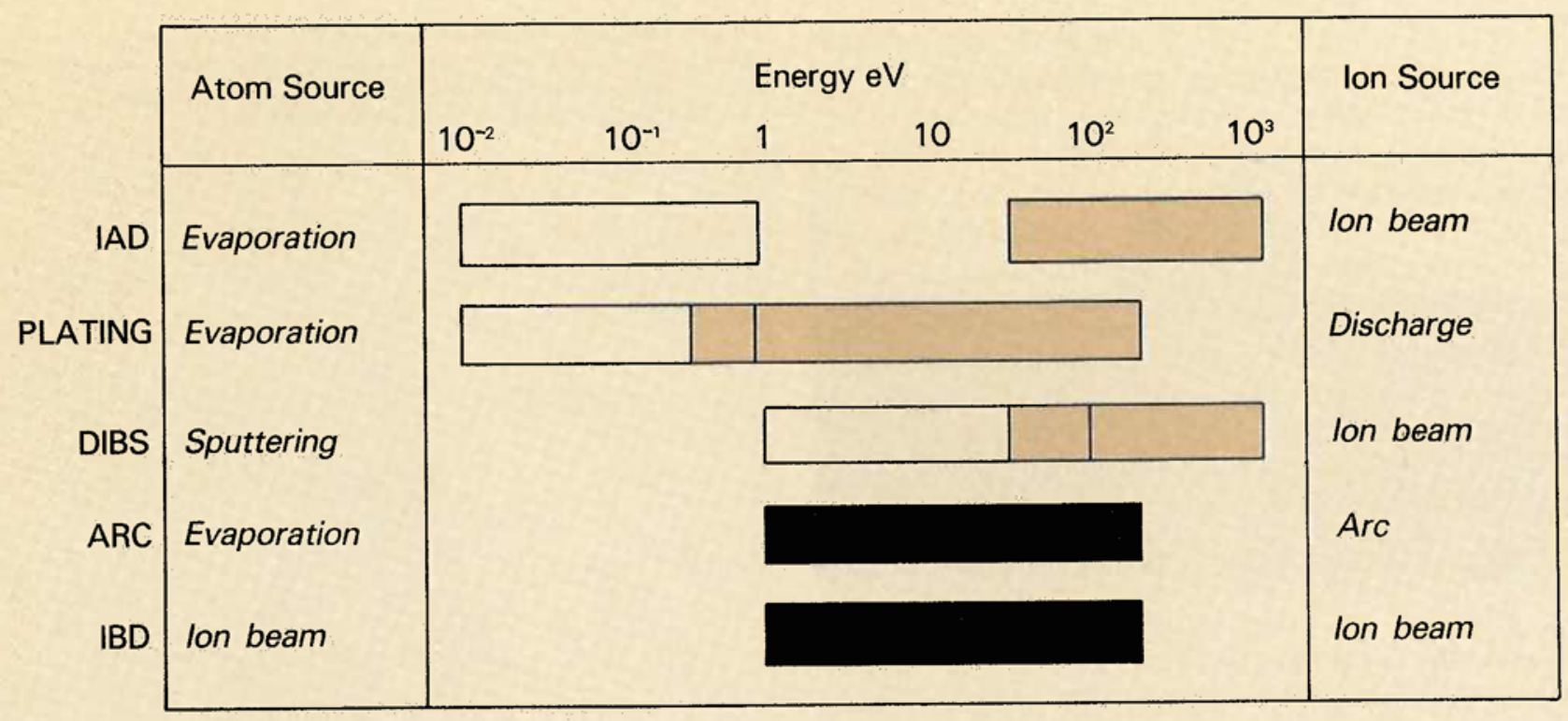

Figure 6 Ion assisted techniques: The energy range of the depositing film atoms and ions present in ion-based vapour deposition techniques.

\section{Ion-Based Deposition Techniques}

The features of the ion-based techniques for gold deposition are summarised in Figure 6. Here the sources of gold atoms and ions are identified in terms of their characteristic energies. The degree of bombardment present during deposition will strongly influence the adhesion of the film to the substrate as well as modify the film structure during growth. The effects of ion bombardment on growing films may be summarised as (23):

a) enhancement of the surface mobility of adatoms

b) stimulation or acceleration of the nucleation and growth of nuclei

c) creation of activated sites that stimulate nucleation

d) development of nucleus orientation

e) recrystallisation of the deposited film

f) increase in bonding energy between the deposited film and substrate

g) decrease in film stress

h) stimulation of chemical reaction for reactive species.

\section{Early Stages of Film Growth}

During condensation an energetic atom or ion loses its velocity component normal to the substrate in order to be physically adsorbed on the surface (24). Some energy will be lost to substrate atoms and the velocity component parallel to the surface enables the atom to move over the substrate. If the adatom collides with other adatoms a critical size nucleus may be formed which will be stable and continue to grow. The number of nuclei formed depends on the adsorption sites, impurities and imperfections, electrostatic charge present on the substrate surface, and the substrate temperature.

The maximum number of nuclei formed is independent of kinetic energy only if the energy is insufficient to create surface defects through sputtering.

The nuclei grow from atoms received from the vapour and any subcritical nuclei available. Coalescence with other stable nuclei eventually results in the formation of a complete and continuous film. The process can be strongly influenced by the energy of the depositing atoms or other energetic ions or neutrals which bombard the growing film. Momentum transfer to the subcritical nuclei and adatoms can increase their mobility. The presence of electrostatic charge on the vapour atoms can also increase surface adatom mobility. Estimates show that a gold vapour atom with a velocity of $10^{3} \mathrm{~m} / \mathrm{s}$ (typical of thermal evaporation at approximately $1000 \mathrm{~K}$ ) can impart a velocity of $0.01 \mathrm{~m} / \mathrm{s}$ to a $10 \mathrm{~nm}$ diameter subcritical nucleus of approximately $10^{5}$ atoms. Theoretically, under typical deposition rates the nucleus can receive enough energy to move a distance of 10 microns on the substrate surface (24).

Energetic particle bombardment can then be expected to greatly increase the surface mobility of adatoms and subcritical nuclei. It has also been observed that ion bombardment can increase crystal orientation at the start of condensation as well as accelerate coalescence (25).

It might therefore be anticipated that any process that can influence the initial stage of film formation, and hence the interfacial atomic layer between the substrate and film, will have a strong influence on the adhesion of the film. 


\section{Gold Film Adhesion — The Effect of Oxygen}

There have been many studies of the adhesion of gold to oxide (e.g. glass) substrates. Mattox (26) has suggested that the adhesion that can be attained is directly proportional to the free energy of oxide formation of the deposited material $(+39 \mathrm{Kcal}$ $/ \mathrm{mole}_{2} \mathrm{O}_{3}$ ). Some models propose that oxides and suboxides exist as a transition region between the substrate and film (27). Oxygen is supplied to this interface by diffusion through the film, consistent with a time-dependent increase in gold-glass adhesion which is frequently observed. It has also been proposed that the oxide surface must have oxygen ions present such that bonding occurs between the film and oxygen surface (28).

Frequently when depositing gold, a layer of an oxygen active metal which has solid solubility with gold is used to increase the adhesion. It has also been reported that gold will diffuse into a silica surface if the gold is melted in the presence of oxygen (29).

Significant improvements in the adhesion of gold to silica were made by sputtering a gold cathode in the presence of an oxygen discharge (26).

The adhesion was assessed by a standard scratch text. The failure loading for films deposited without any discharge was less than $5 \mathrm{~g}$ whereas the best films survived a $600 \mathrm{~g}$ load. However, it was found that all films failed if heated to $250^{\circ} \mathrm{C}$ in vacuum.

Ion bombardment during film growth was reported by Franks et al., (30) to improve gold adhesion on several substrates. Gold was evaporated from a thermal evaporation source, and the substrate and film bombarded with $5 \mathrm{keV}$ argon ions. It was found that gold films on sapphire and on glass could be removed by adhesive tape (tape test for adhesion), but adhesion was improved by deposition of an interfacial chromium layer. Good adhesion was found for gold on silicon and on germanium. No figures were given for the relative arrival rates of gold atoms to argon ions and no other energies or ion species investigated.

Similar experiments were performed by Nandra et al., (31) for gold on copper. Here the ion energy was varied from $0.8-6 \mathrm{keV}$ the ion current density from $0.02-0.7 \mathrm{~mA} / \mathrm{cm}^{2}$ and the deposition rate from $0.02-2 \mu \mathrm{m} / \mathrm{min}$. Both the scratch and tape tests were used to assess adhesion. The main conclusion reached was that sputter cleaning prior to deposition was the most effective means of producing highly adherent coatings and that bombardment during deposition improved adherence only slightly. Oxygen and argon bombardment of oxides prior to gold deposition has also been demonstrated to have little effect on the resulting adhesion (32).

Significant improvements in gold adhesion to glass and silicon have been found for oxygen ion assisted deposition $(33,34)$. Gold was evaporated by electron-beam bombardment
Table 1. Failure loadings as measured by the scratch test for various substrates under various pre-cleaning and film depositions. Ion-assistance was carried out at $1 \mathrm{keV}$

\begin{tabular}{lllr}
\hline Preparation & & \multicolumn{2}{l}{ Failure loading (g) } \\
conditions & Substrate & $65 \mu \mathrm{m}$ & $250 \mu \mathrm{m}$ \\
\hline Evaporation (no ions) & Glass & 0,7 & 2 \\
Argon pre-clean & Glass & 1 & 2 \\
& Si & 0,4 & 1 \\
Argon pre-clean + ion & Glass & 1 & 2 \\
assisted $\left(\right.$ Ar $\left.^{+}\right)$ & & & $>2000$ \\
Oxygen pre-clean +ion & Glass & 150 & $>2000$ \\
assisted & Si & 300 & \\
& & & \\
\hline
\end{tabular}

and the depositing film irradiated with $100 \mathrm{eV}$ and $1 \mathrm{keV}$ ions from a Kaufman source $\left(2 \mathrm{~A} / \mathrm{m}^{2}\right.$ at a deposition rate of $0.2 \mathrm{~nm} / \mathrm{s}$ ). Other ion species investigated were argon and hydrogen. Films were prepared both with and without ion bombardment and the adhesion checked by scratch testing. The results are shown in Table I. The best adhesion was found for films deposited when the substrate was pre-cleaned by oxygen-ion bombardment and the gold film ion-assisted to at least the point of film coalescence. When prepared under these conditions the film could not be removed by scratch testing with a $250 \mu \mathrm{m}$ radius tip (standard scratch test size) at the highest practical loading of $2 \mathrm{~kg}$. The tests were also performed with a $65 \mu \mathrm{m}$ radium tip, but under these conditions the tip partially damaged the substrates before any film failure was evident.

If gold is oxygen-ion-assisted to its final thicknoss, i.e. throughout the whole deposition process, the films appear less reflective than normally evaporated gold. Figure 7 shows the reflectance and optical properties of ion-assisted and normally evaporated gold. The changes in the optical properties are associated with oxygen trapped in voids in the film and can be modelled assuming a mixture of 82 per cent gold and 18 per cent oxygen in the Maxwell-Garnett theory (34), where the effective complex refractive index $N^{*}$ of the gold film is given by:

$$
q \frac{N^{2}-1}{N^{2}+2}=\frac{N^{* 2}-1}{N^{* 2}+2}
$$

where $q$ is the packing density, and $N$ the complex refractive index of evaporated gold. The theoretical reflectance for this system is shown in Figure 7. The actual oxygen concentration in the film was measured to be approximately 10 per cent. 


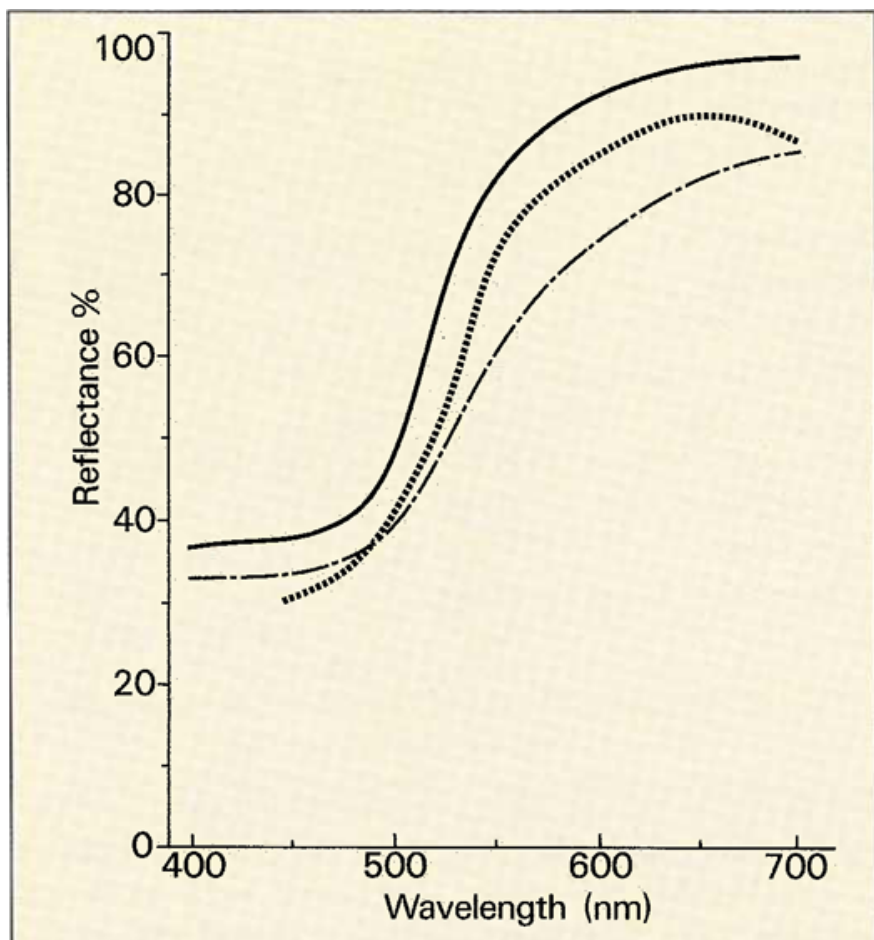

Fig. 7 Reflectance of gold films produced by evaporation (solid line) and oxygen-ion-assisted deposition (broken line). Dotted line is a theoretical calculation assuming 0,82 packing density for gold ( 34 ).
The gold films do not have to be oxygen-ion bombarded throughout the whole deposition to achieve high adhesion. In practice it is only necessary to assist the film to the point of continuous film formation. This point can be estabilshed by monitoring the transmittance of the film or the electrical resistance between two isolated conductors on the glass substrate

The mechanism involved in ion-induced enhancement of gold adhesion to glass is not simply sputter-cleaning of the substrate surface, since argon bombardment does significantly improve adhesion. A recent systematic study (35) of the nucleation and growth of films of gold on glass substrates by optical and ion-scattering techniques has given some insight into the mechanism.

The apparatus used to monitor the properties of gold films deposited with and without ion bombardment (36) is shown in Figure 8 . The films were deposited by electron-beam evaporation and the optical properties measured by transmittance and reflectance of a light source (400-700 $\mathrm{nm}$ wavelength), and also, in greater detail, by ellipsometry. Ellipsometry permits sensitive measurements of change in film thickness and optical properties by analysis of the state of polarisation of light reflected off the substrate and film surface (37). The composition of the film was determined by ion scattering spectroscopy (38), which was used to establish the point of coalescence of the gold films on the substrate beam evaporation.

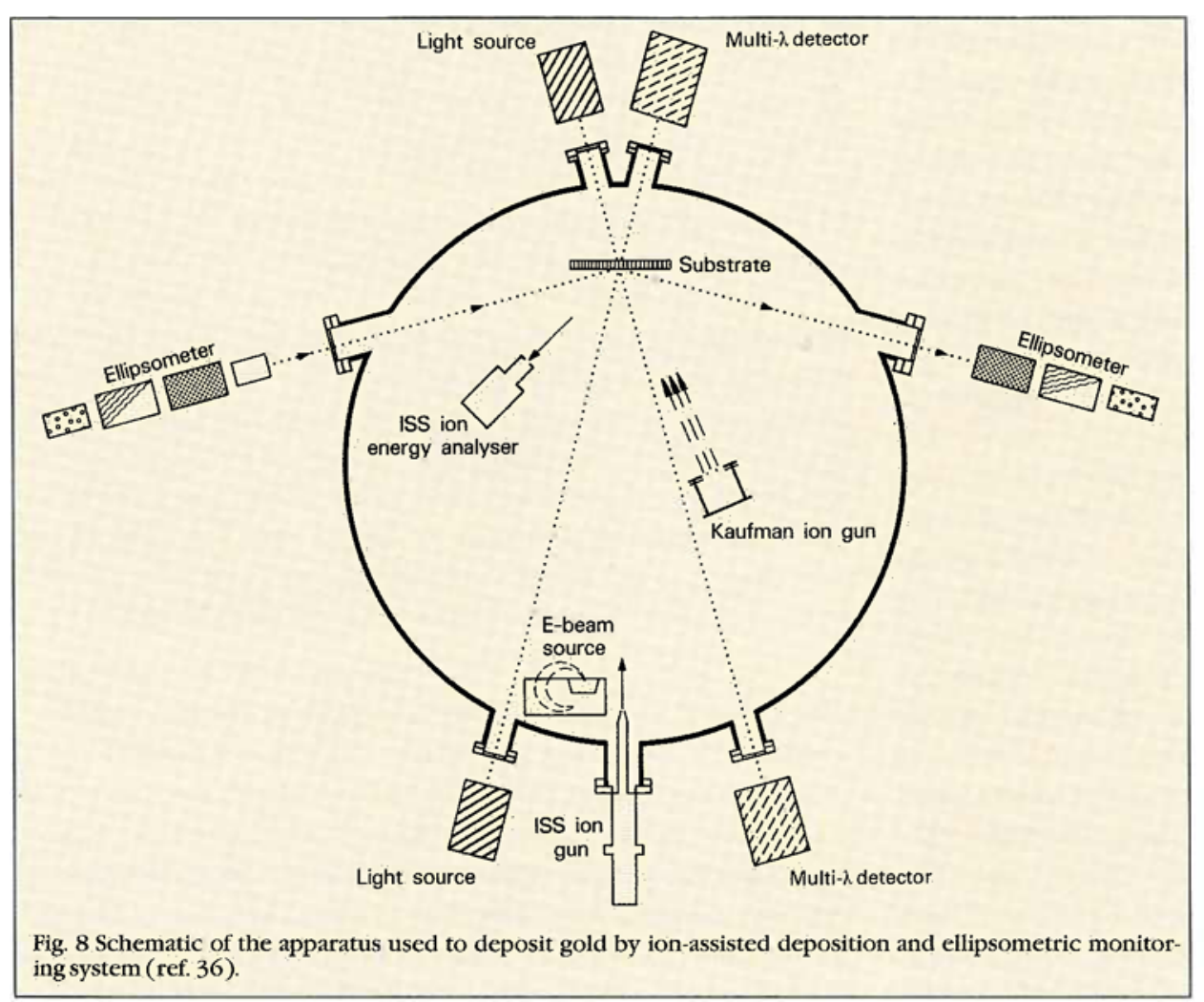

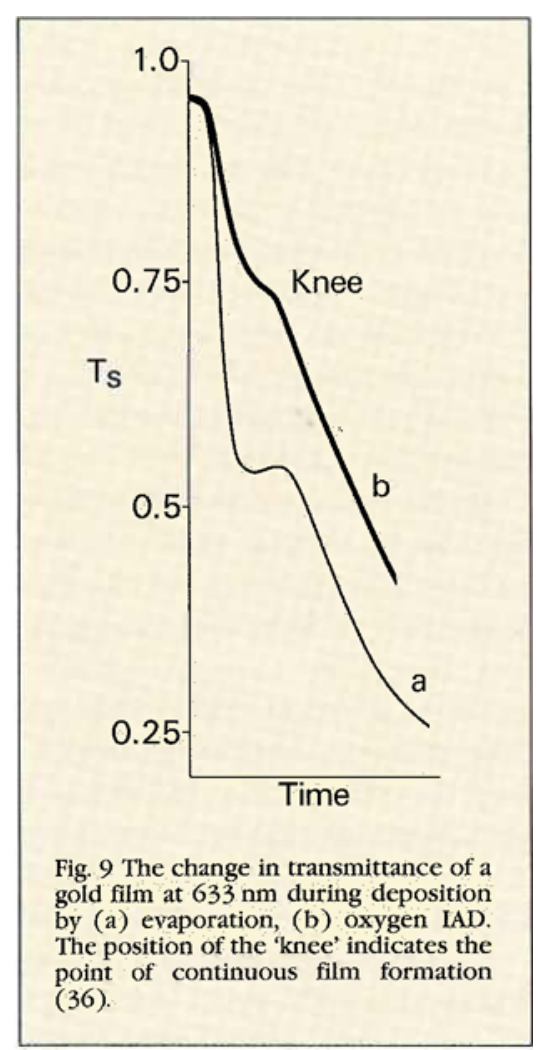

Gold Bull., 1986, 19, (4) 


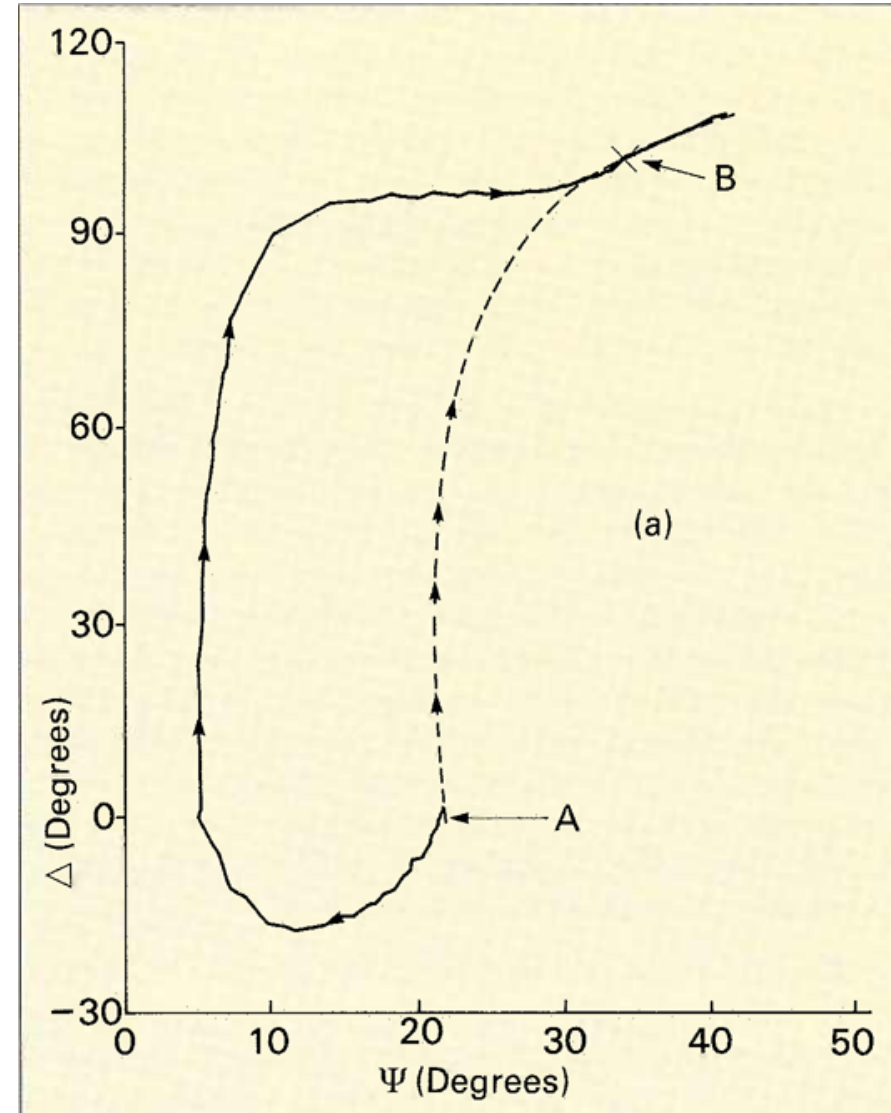

Fig. 10 The changes in ellipsometric angles $\Delta$ and $\psi$ during film growth for gold films deposited by (a) evaporation, (b) oxygen IAD and (c) argon IAD. The broken line is the theoretical plot for a film deposited with bulk optical properties (continuous layer) from the start of the deposition (36).

The change in transmittance of a gold film during deposition by electron-beam evaporation is shown in Figure 9. The knee in the trace occurs at the point where the optical properties are changing rapidly due to coalescence of the gold film, and marks the point of continuous film formation. When the film was deposited under $100 \mathrm{eV}$ oxygen ion bombardment the knee occurred at a much earlier stage in the deposition.

The change in coalescence thickness was also detected in the ellipsometric data. Figure 10 a shows the variation in the ellipsometer angles $\Delta$ and $\psi$ for a growing gold film produced by evaporation. The locus of the curve starts at the position of a clean substrate, point $A$, where $\Delta$ is zero. The film is deposited to point B where coalescence occurs. The broken line is a theoretical calculation for gold film growth, assuming the film is deposited as a continuous layer with bulk optical properties from the start of the deposition. The results showed that a continuous gold film was produced at approximately $18 \mathrm{~nm}$, in close agreement with the value of $16 \mathrm{~nm}$ of Andersson and Norrman (39). In the case of oxygen IAD, the ellipsometric data indicated that coalescence occurred much earlier at approxi-
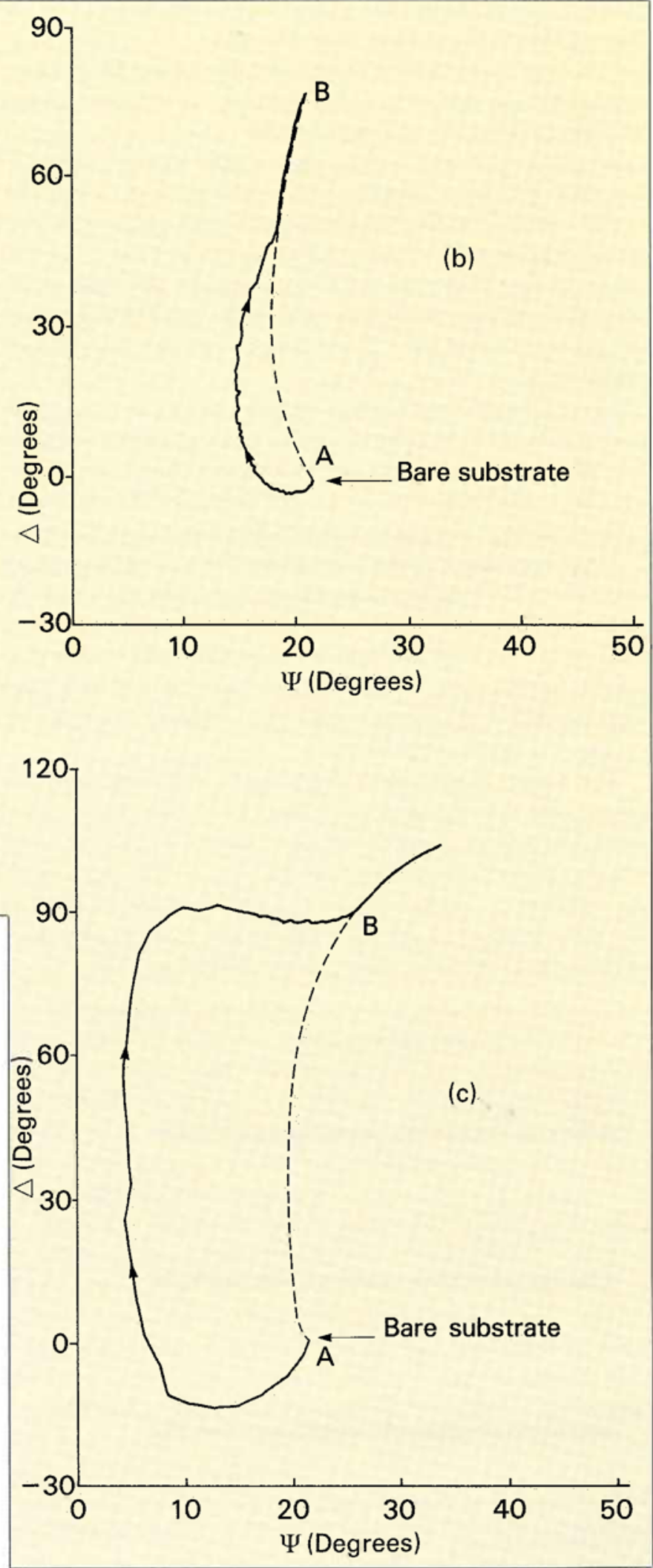
mately $4 \mathrm{~nm}$ (Figure 10b). However, for argon IAD (Figure 10c), no significant changes were observed.

The greatly increased adhesion of gold to silica has been interpreted as a consequence of an increase in the area of contact between the gold film and the substrate.

An idealised model of the shape of gold islands before coalescence has been proposed by Norrman et al., (40). The model assumes that the film islands, at the point of coalescence, can be represented by spheroids as shown in Figure 11 a. Immediately after coalescence the islands merge and form (a) an interfacial voided layer between the silica surface and film, and (b) an outer surface layer These layer thicknesses are indicated in Figure 11 .

In the case of oxygen ion assistance the shape of the spheriods is thought to be substantially modified as shown in Figure 11b. When coalescence occurs under these conditions, the interfacial voided region is no longer presented. Furthermore, the outer surface roughness is also reduced from 2.6 to $0.7 \mathrm{~nm}$.

These experiments also demonstrated that once the point of coalescence had been reached, either with or without ion-assistance, the film could be etched back by ion bombardment to a much thinner, continuous film thickness than was possible during the growth state. Continuous gold films as thin as $0.7 \mathrm{~nm}$ were produced by etching a gold film originally deposited by oxygen-ion-assisted deposition.

The density of gold mines deposited by ion-assistance is also greater than that of evaporated films (41). The density of evaporated gold was measured to be approximately $17.5( \pm 0.5) \mathrm{g} / \mathrm{cm}^{3}$ whereas oxygen ion-assisted film densities of $19.8( \pm 0.5) \mathrm{g} / \mathrm{cm}^{3}$ are achievable. The bulk density of gold is about $19.29 \mathrm{~g} / \mathrm{cm}^{3}$. The enhancement in adhesion for oxygen IAD has also been observed gold on mylar, teflon, plastic and perspex (41).
The major effect of oxygen ion assistance on the nucleation and growth of thin gold films is then (a) to promote nucleation such that coalescence is accelerated and (b) to enhance wetting of the gold islands to the silica surface. This latter effect is presently thought to the principle reason for the improvement of film adhesion. The reasons for the enhancement of the wetting of the gold islands is not yet understood. The process may be related to gold-oxygen or gold-oxygen-silicon bonding at the substrate-film interface due to the presence of oxygen ions.

The increased wetting of the gold to the substrate may be the consequence of the formation of a stable gold oxide at the film-substrate interface. It has been proposed that gold oxide can form at high temperatures and diffuse into the surface of glass (29). Shishakov (42) has reported on the structure of $\mathrm{Au}_{3} \mathrm{O}_{2}$ prepared by heating gold to $500^{\circ} \mathrm{C}$ in an oxygen atmosphere. The oxide $\mathrm{Au}_{2} \mathrm{O}_{3}$ has been produced by oxygen reactive sputtering and found to be reduced to $\mathrm{Au}_{2} \mathrm{O}$ by thermal treatment (43). Electrochemical reactions can also produce $\mathrm{Au}_{2} \mathrm{O}_{3}$ on the surface of gold (44). It is possible that such stable oxides are produced by the interaction of energetic oxygen ions with gold and may influence film nucleation processes, although as yet no direct evidence has been obtained.

The observation of a time-dependent increase in adhesion of gold to glass can be intepreted as a result of the mobility of the voids at the film-substrate interface. Nakahara (45) has suggested that the excess vacancies present in a freshly deposited film can be annihilated by diffusing to various sinks available in the film. This may lead to an increase in the area of contact of the film to the substrate over a period of time. In the case of oxygen-ion-assisted films, the interfacial voids are already reduced to a minimum and maximum adhesion is attained.

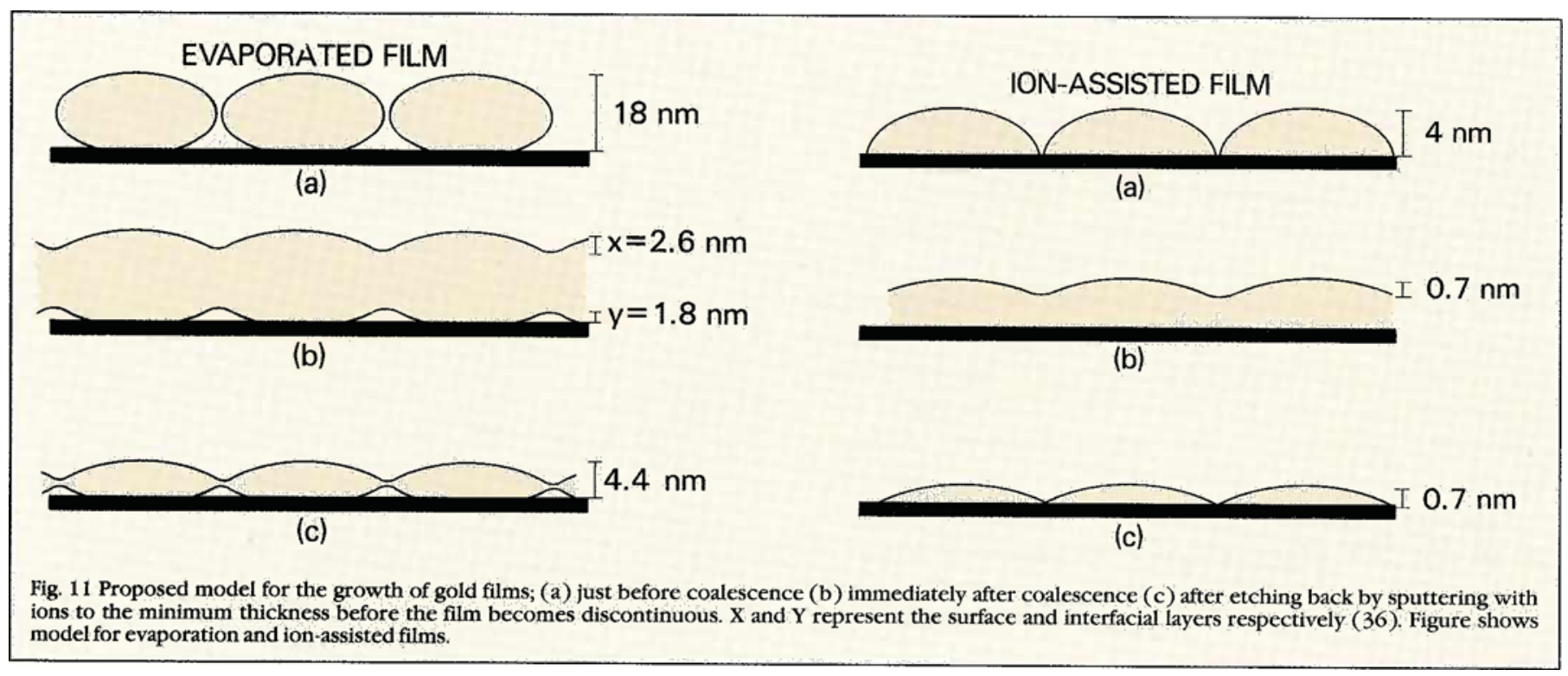




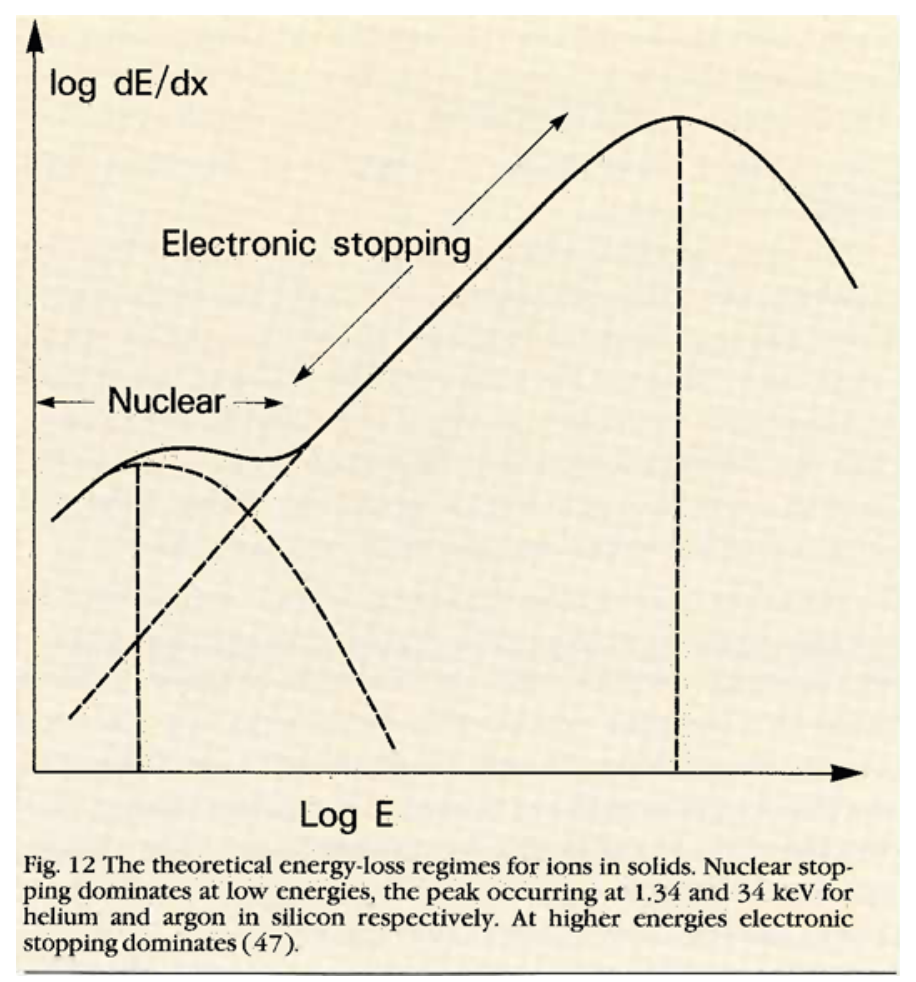

\section{The Influence of Atomic Mixing on Adhesion}

The interaction of an energetic ion with a solid is a complex process in which many events occur simultaneously. At low energies, sputtering of the surface atoms will dominate. The cascades created in the surface layers can lead to a mixing of the substrate and film atoms (46). If deposition continues during mixing, the collisions will eventually be confined to the film atoms alone.

It is also possible for the diffusion of the film atoms into the substrate to be enhanced due to the creation of lattice defects by the incident radiation. The amount of energy transferred from the ion to the substrate atoms depends upon the stopping power or energy loss per unit length (49). At the lowest velocities of heavy and medium-mass ions, the energy transfer is dominated by nuclear collisions, as shown in Figure 12. At higher velocities, particularly for low-mass ion irradiation in the $\mathrm{MeV}$ energy range, the energy is lost almost entirely by energy transfer to the target atom electrons (electronic stopping regime). Beyond the stopping-power maximum, the ion is stripped of its electrons.

The influence of ion bombardment on film-substrate interfaces therefore depends very greatly on its energy, nuclear events dominating at low energies (sputtering, mixing etc.) and electronic events at high energies (excitation, ionisation, etc.).

The adhesion of thin films to substrates can be greatly improved by a technique based on dual-beam-sputtering. The technique is known as dynamic recoil mixing (DRM). The material to be deposited is sputtered from a target onto the substrate by an ion beam ( $1 \mathrm{keV}, 1 \mathrm{~mA} / \mathrm{cm}^{2} \mathrm{Ar}^{+}$). At the same time the film is bombarded with a second ion beam of higher energy (10 keV, $10 \mathrm{~A} / \mathrm{cm}^{2} \mathrm{Ar}^{+}$). During bombardment, the conditions are adjusted to maintain a dynamic balance between resputtering of the film and deposition. A mixing process then occurs at the substrate film interface leading to enhanced bonding, particularly for gold on silicon.

The work of Argyrokastritis et al., (48), has demonstrated the effectiveness of the technique. Gold films were initially sputter deposited to a thickness of $10 \mathrm{~nm}$ onto silicon substrates and then subsequently bombarded with $10 \mathrm{keV} \mathrm{Ar}{ }^{+}$ions with fluences of $5 \times 10^{14}$ and $1 \times 10^{16}$ ions $/ \mathrm{cm}^{2}$ whilst deposition continued. The faction $f$ of gold atoms transmitted through the interface is given by

$$
f=\left(\sigma^{2}-\sigma_{\alpha}^{2}\right) / \sigma_{o}^{2}
$$

where $\sigma$ and $\sigma_{o}$ are the standard deviations of the 'as deposited' gold film and that of the DRM film respectively. The total number of recoil-implanted gold atoms or is then

$$
o r=f N
$$

where $N$ is the number of gold atoms in the film before ion bombardment. The number of recoil implanted gold atoms increased with argon fluence from $10^{15}$ to $10^{17}$ recoil atoms $/ \mathrm{cm}^{2}$ for fluences of $10^{15}$ to $10^{16} \mathrm{ions} / \mathrm{cm}^{2}$. The recoil yield $Y_{r}=\sigma_{r} / \sigma_{o}$ (the number of gold atoms recoil implanted per incident ion) was determined for initial gold layer thicknesses ranging from 7 to $28 \mathrm{~nm}$ and is shown in Figure 13. The ion energy was 10 $\mathrm{keV}$ and fluence $5 \times 10^{15}$ ions $/ \mathrm{cm}^{2}$. The data show that the value of $Y_{r}$ increases at layer thickness less than $7 \mathrm{~nm}$ and is in good agreement with computer calculations over the measured range. The calculated yield also indicates a peak at $5 \mathrm{~nm}$. The minimum film thickness for a continuous gold layer is also expected to occur at a similar thickness from measurements based on IAD. The sputter deposited film is probably fully coalesced at a thickness less than that of an evaporated layer due to the influence of the higher arrival-energy of sputtered atoms and also reflected Ar ions.

DRM has also been shown to produce ion-bombardmentinduced reactions between gold and silicon (49). In this work higher energy Ar ions of $30 \mathrm{keV}$ were used to bombard an initial $30 \mathrm{~nm}$ thick gold film deposited on silicon. Under dynamic conditions it was established that a metastable amorphous silicide $\mathrm{Au}_{76} \mathrm{Si}_{24}$ was formed on top of the silicon. Gold silicide formation has also been observed (50) for $200-300 \mathrm{keV}$ ion bombardment of gold films the principal phases being $\mathrm{Au}_{5} \mathrm{Si}_{2}, \mathrm{Au}_{5} \mathrm{Si} ; \mathrm{Au}_{10} \mathrm{Si}_{3}$ and $\mathrm{Au}_{3} \mathrm{Si}$.

The influence of DRM on gold bonding to silica has been recently examined in detail (51). The results were sensitive to the cleaning process used in the preparation of the substrate (52). 


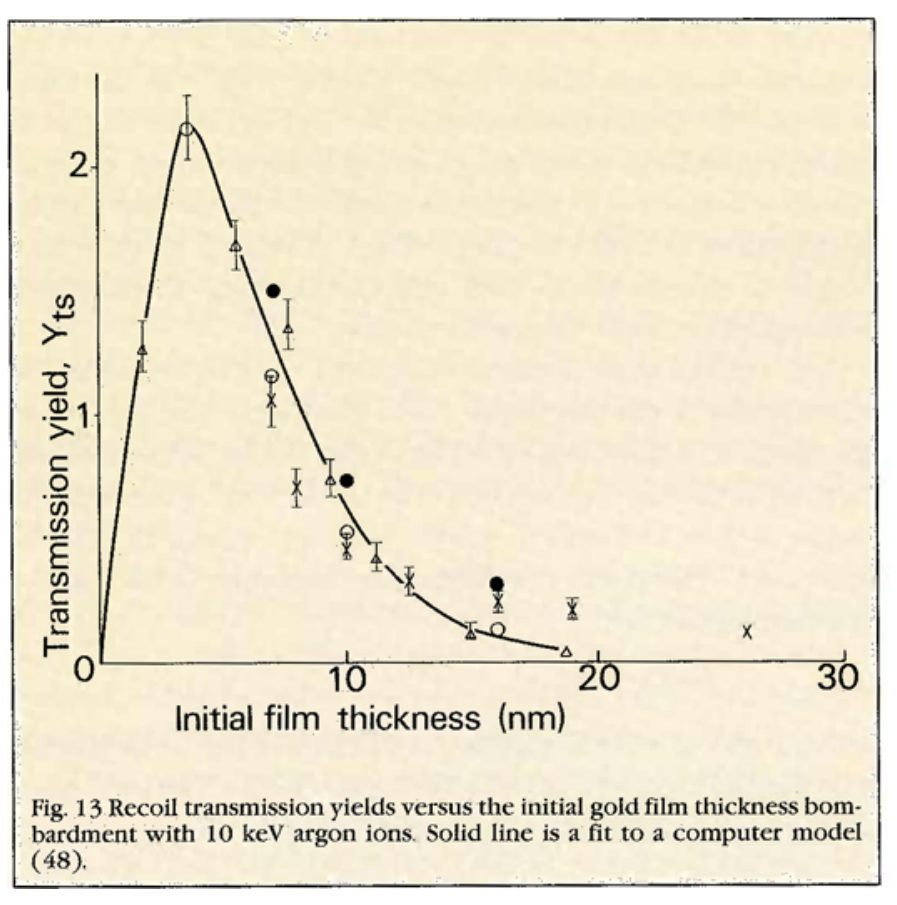

The best substrate preparation required ultrasonic degreasing, rinsing in deionised water, ultrasonic rinsing in a stream of deionised water and finally rinsing in isopropyl alcohol before drying in a flow of dry nitrogen. After coating, the adhesion was estimated by a pull test. In this method the coated silica substrates were cemented between steel rods and a tensile testing machine used to pull the rods apart. The critical load at which bonding failure occurred was then taken as an indication of the adhesive strength. The results showed that after a fluence of $1 \times 10^{17} \mathrm{Ar}$ ions $/ \mathrm{cm}^{2}$ on an initial $10 \mathrm{~nm}$ gold film, the adhesion of the gold was increased by a factor of 30 compared with sputtered films.

\section{Post-Irradiation of Gold Films}

Ion enhanced adhesion of gold films to silicon, gallium arsenide, silica, sapphire, teflon, ferrite and alumina substrates has been achieved by irradiating the deposited film with higher energy ions (53). The energy of the ions used varies from $0.1-21 \mathrm{MeV}$ and the species may be inert or reactive gas ions. Before the gold is deposited by either evaporation or sputtering the substrate is first carefully cleaned (52). The film is then bombarded with the ion beam and the adhesion assessed by the tape method, scratch testing or a simple abrasive rub test.

In a study using $0.1 \mathrm{MeV}$ inert gas ion beams (54) a $10 \mathrm{~nm}$ layer of gold was deposited, subjected to ion bombardment and further film deposition continued to a final thickness of $500 \mathrm{~nm}$. Figure 14 shows the adhesion, as assessed by scratch failure loading, as a function of ion dose for $100 \mathrm{keV} \mathrm{Kr}$ ions. It can be seen that the adhesion is increased to a maximum of approximately $20 \mathrm{~g}$ at a dose of $2 \times 10_{15} \mathrm{ions} / \mathrm{cm}^{2}$. The mechanism for this enhancement in adhesion has been related to the process of recoil implantation, as proposed in the initial stage of DRM.

The gold atoms are effectively knocked forward into the substrate over a distance of about 1-10 nm by the incident ions. It was also suggested that electronic collisions in the interfacial region may influence the adhesion. The initial $10 \mathrm{~nm}$ of gold will also be a discontinuous film if deposited by evaporation. This has been determined by the recent IAD studies. The incident ion beam may therefore modify the wetting of the gold at the substrate interface and this can increase adhesion.

The effect of increasing the energy of the ion irradiation of the $\mathrm{MeV}$ region is to reduce the degree of atomic mixing at the film-substrate interface (46). The mixed layer thickness for a metal on a dielectric produced by $\mathrm{MeV}$ energy ions has been measured to be approximately $1.5 \mathrm{~nm}$, which is much less than the case for low-energy ion mixing or direct implantation (55). It is therefore probable that the mechanism for enhanced adhesion at $\mathrm{MeV}$ ion energies is different to that for the lowenergy case.

Wie et al. (55) deposited $35 \mathrm{~nm}$ thick films of gold on cleaned silica substrates by thermal evaporation and postirradiated with high-energy chlorine $\left(\mathrm{Cl}^{+}\right)$ion beams. The results are summarised in Figure 15. It was found that the thre shold dose (dose above which samples passed the tape test) for high doses varied with energy as expected from the variation in the electronic stopping power of the $\mathrm{Cl}$ ion beam in silica. However, it was established that a low-dose threshold also existed which was independent of energy. These results point to two distinct adhesion mechanisms, one for low doses and one for high doses. In the case of low ion doses, microcracks were observed in the surface of the silica. These cracks closed up at the higher doses. The origin of the surface crazing was due to non-uniform stress relaxation of ionisation compaction of the surface (56) (the compaction of silica under $15 \mathrm{MeV} \mathrm{Cl}$ bombardment was $180 \mathrm{~nm}$ ). The surface crazing may be responsible for the improved bonding of the gold to the substrate.

The high-energy mechanism is presently considered to be a type of spot-weld or stitching process which dominates when the incident ion is near the peak of the electronic stopping region. A high-temperature electron spike may form around the track of each ion as it penetrates the substrate, stitching the film at the interface.

Similar experiments were also performed on gold films deposited on glass by both evaporation and sputtering (57). The film thickness was varied from 55 to $197 \mathrm{~nm}$ and $2 \mathrm{MeV}$ helium $\left(\mathrm{He}^{2+}\right)$ used for irradiation. The films did not exhibit any improvement in adhesion, but positive results were obtained for 


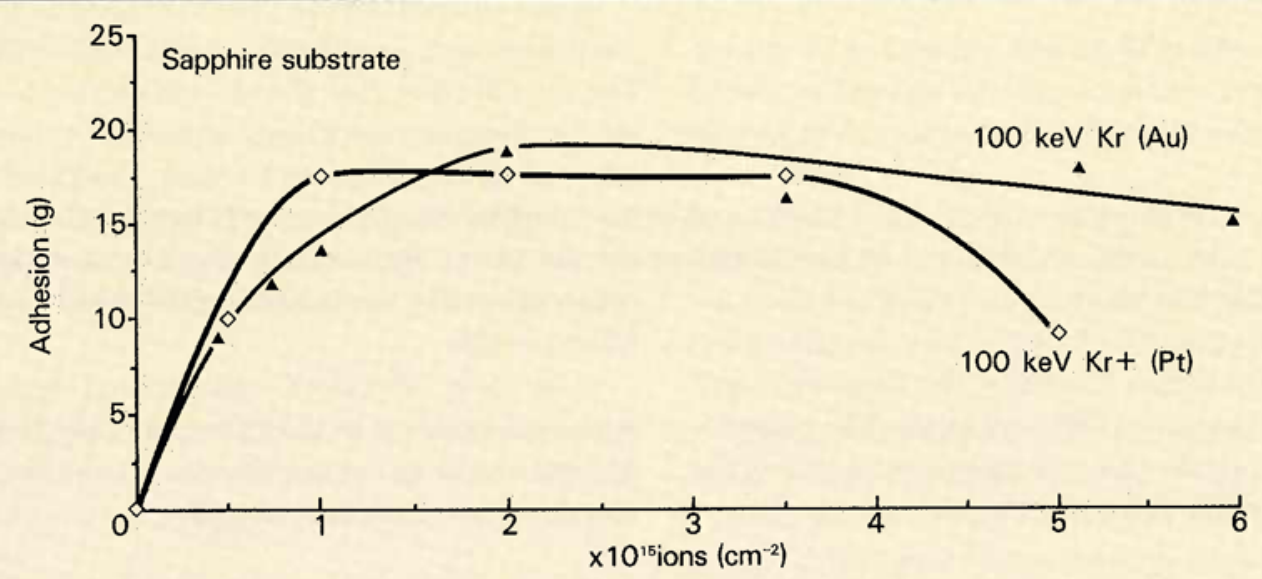

Fig. 14 The adhesion enhancement for $500 \mathrm{~nm}$ platinum and gold films deposited on ion bombarded $10 \mathrm{~nm}$ films deposited on sapphite ( 54 ).

aluminium films. The reason for this negative result is not clear and may be related to the initial substrate prepartion or the range of thicknesses of the gold films studied.

Thin-film stitching has also been observed for electron irradiation of $20 \mathrm{~nm}$ thick gold films sputter-deposited onto silicon (58). The adhesion was improved by irradiating the surface with 5-30 keV electrons in an electron microscope. The mechanism is purely electronic in nature since the electron energies are below that required to displace the atoms at the interface. However, it was found that the electron stitching process did not work when the gold films were deposited by evaporation. This result is again most probably due to the discontinuous nature of thin gold films produced by evaporation as opposed to sputtering. This is supported by more recent observations of a positive result for $10 \mathrm{keV}$ electron irradiation of $55 \mathrm{~nm}$ thick evaporated films (57).

Low-energy electron irradiation has also been demonstrated to improve the adhesion of gold to silicon (59). When the native oxide on the surface of silicon was irradiated with $1.3 \mathrm{keV}$ electrons, a partial decomposition of $\mathrm{SiO}_{2}$ occurred. Subsequent deposition of gold produced highly adherent layers. The gold adhesion on silicon was found to be good whenever gold atoms were able to bond directly to silicon. Good adhesion was observed for gold deposited directly on a clean silicon surface without any electron irradiation.

These results indicate that to achieve high adhesion it is necessary to clean the substrate in situ, and maintain the clean surface prior to gold deposition. The surface will remain 'clean' only if it is maintained under ultra-high vacuum conditions (less than $10^{-7} \mathrm{~Pa}$ ) where the monolayer formation time is of the order of several hours.

The mechanism for silicon oxide reduction under electron impact is also not clear, although the possibility of dissociation of $\mathrm{SiO}_{2}$ by momentum transfer from the electron may be ruled out since the maximum energy is too low to break the chemical bond, i.e. the same as in the case of MeV particle irradiation. It has been suggested that the silicon-oxygen bond is broken by the excitation of oxygen to an ionic state (60). The ions are then desorbed and may be neutralised resulting in a release of neutral oxygen. Low-energy ion irradiation can also lead to a depletion of oxygen from the surface of silica (61).

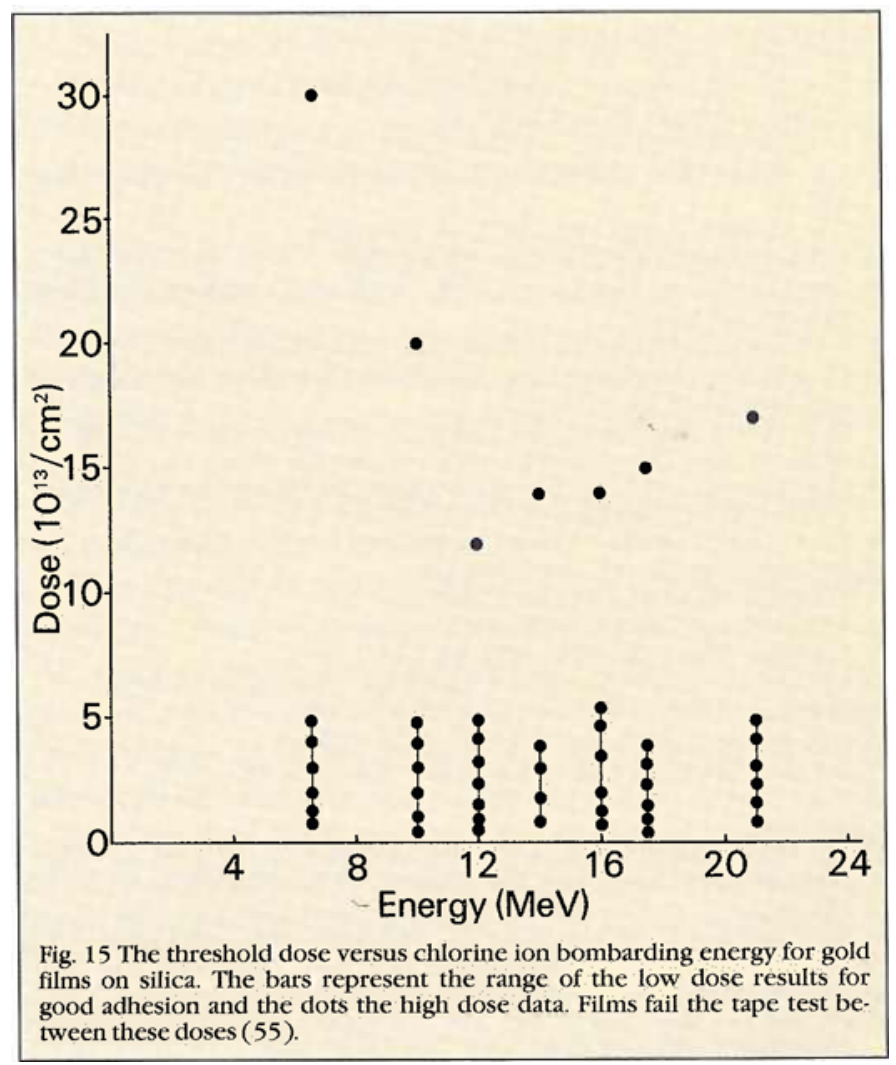




\section{Summary}

The review of the effects of particle irradiation on the adhesion of gold ions to various substrates has shown that several mechanisms may be responsible for the enhancement of gold film bonding

In the first instance the substrate surface must play a vital role in the maximum achievable adhesion and its preparation is a critical element. The film structure and initial adhesion are also highly dependent upon the film deposition process that is used. The degree of ionisation present in the deposition process has a marked influence on film properties. The presence of reactive oxygen can modify the wetting characteristics of the gold to the substrate, even in the case of very low-energy ions.

Acknowledgements: The author wishes to thank Dr. K Muller for pro viding advanced copies of computer simulations and Mr. W,G. Sainty for helpful discussions.
When medium-energy ion bombardment is employed dur ing film growth, atomic mixing effects dominate and lead to enhanced adhesion and silicide formation. At higher energies, where electronic processes appear to dominate, the film is 'stitched' to the substrate by local regions of high bonding at the interface, or the surface is crazed and the gold anchored to the substrate. The studies of electron reduction of surface oxides show that when silicon-gold bonding dominates the adhesion is high.

It is clear, therefore, that several regimes of particleenhanced bonding of gold to silica and other materials exist and that two or more mechanisms may be operating for a given set of experimental parameters.

\section{References}

1 R Jacobsson, Thin Solid Films, 1976, 34, 191-199

2 K. Kendall, f. Pbys. D, 1971, 4, 1186-1195

3 D.W. Butler, C.D.H. Stoddart and T.R. Stuart, J.Pbys. D, 1970, 3, 877-883

4 P. Benjamin and C. Weaver, Proc. Roy. Soc., 1960, A254, 163-176

5 R.S. Sabirov, Sou.J. Opt. Technol., 1982, 49,171-172

6 W. Heitmann, Appl. Optics, 1971, 10, 2414-2419

7 P.J. Martin, J.Mater. Sci., 1986, 21, 1-25

8 D.M. Mattox, J. Vac. Sci.Tecbnol., 1973, 10,47-52

9 D. Teer, J.Pbys. D, 1976, 9, L187-189

10 M. Kobayashi and Y. Doi, Thin Solid Films, 1978, 54, 67-74

11 A.A. Plyutto, V.N. Ryshkov and A.T. Kapin, Soviet Pbys. JETP, 1965 328-337

12 C.W. Kimblin, J. Appl. Phys., 1973, 44, 3074-3081

13 T. Utsumi, Appl. Phys. Lett., 1971, 18, 218-220

14 V.M. Lunev, V.G. Padalka and V.M. Khoroshikh, Instrum. Exp. Tech., $1976,19,1465-1467$

15 T. Utsumi and J.H. English, J. Appl. Pbys., 1975, 46, 126-131

16 I.I. Aksenov, V.A. Belous, V.G. Padalka and V.M. Khoroshikh, Instrum. Exp. Tech., 1978, 21, 1416-1418

17 M. Krohn, K.P Meyer and H. Bethge, J. Crystal Growth, 1983, 64, 326332

18 H.H. Anderson and H.L. Bay in 'Sputtering by Particle Bombardment I', R. Behrisch (ed), Springer N.Y., 1981, 145-209

19 KL. Chopra, Thin film Phenomena, McGraw-Hill N.Y, 1969

20 Dubilier Scientific Ltd. Abingdon, U.K.

21 T. Takagi, Vacum, 1986, 36, 27-31

22 K.H. Muller, J. Vac. Sci. Tecbnol., (in press)

23 T. Takagi, Thin Solid Films, 1981, 92,1.17

24 K.L. Chopra and M.R. Randlett, J. Appl. Pbys., 1986, 39, 1874-1881

25 M. Marinov, Thin Solid Films, 1971, 46, 267-274

26 D.M. Mattox, J. Appl. Phys., 1966, 37, 3613-3615

27 M.P. Borom and J.A. Pask, J. Am. Ceram. Soc., 1966, 19, 1.5

28 W.A. Weyl in 'Coloured Glasses', Soc. Glasstech., Sheffield, 1951 333-339

29 D.C. Moore and H.R. Thornton, J. Res. Natl. Bur. Std., 1959, 62, 127-135

30 J. Franks, P.R. Stuart and R.B. Withers, Thin Solid Films, 1976, 60 $231-236$

31 S.S. Nandra, F.G. Wilson and C.D. DesForges, Thin Solid Films, 1983 , 107, 335-344

$32 \mathrm{~J}$. Salem and F. Sequeda, $J$. Vac. Sci. Technol, 1981, 18, 149-152

33 P.J. Martin, W.G. Sainty and R.P. Netterfield, Appl. Opt., 1984, 23 $2668-2669$
34 PJ. Martin, W.G. Sainty, R.P. Netterfield and A.N. Buckley, Vacumm, 1985 $35,621-624$

35 R.P Netterfield and P.J. Martin, Appl. Surface Sci, 1986, 25, 265-278

36 R.P. Netterfield, P.J. Martin, W.G. Sainty, R.M. Duffy and C.G. Pacey, Sci. instr., 1985, 56, 1995-2003

37 WEJ Neal, Appl Surface Sci. 1974, 2, 445-501

38 W.L. Baun, Surface Interface Anal., 1981, 3, 243-250

39 T.G. Andersson and S.H. Norrman, Vacuum, 1977, 27, 329-333

40 S. Norrman, T. Andersson, C.G. Granquist and O. Hundrei, plyss. Rev, $1978, \mathbf{B 1 8}, 674-695$

41 W.G. Sainty (Private communication)

42 N.A. Shisakov, Soviet Phys. Crystl., 1957, 2, 674-676

43 J.J. Pireaux, M. Liehr, P.A. Thiry, J.P. Delrue and R. Caudano, Surf. Sci., $1984,141,221-232$

44 M. Peuckert, F.P. Coenen and H.P. Bonzel, Surface Sci, 1984, 141, 515-532

45 S. Nakahara, Tbin Solid Fitms, 1979, 64, 149-161

46 G. Carter and D.G. Armour, Thin Solid Films, 1981, 80, 13-29

47 P. Sigmund in 'Sputtering by Particle Bombardment I', R. Behrisch (ed), Springer N.Y., 1981, 9-67

48 P. Argyrokastritis, D.S. Karpuzov, J.S. Colligon, A.E. Hill and H. Kheyrandish, Pbil. Mag. A, 1984, 49, 547-556

49 A. Komissarov, H. Kheyrandish and A.Y. Al-Tamimi, Thin Solid Films, $1986,137,267-279$

50 B.Y. Tsaur, J.W. Mayer and M.A. Nicolet in 'Proc. Conf, on Ion Implantation Metallurgy', Warrandale 1980, 142-151

51 N.A.G. Ahmed, J.S. Coligon and A.E. Hill, Thin Solid Films (in press)

52 D.M. Mattox, Thin Solid Films, 1985, 124, 3-10

53 J.E. Griffith, Y. Qiu and T.A. Tombrello, Nucl. Instr, and Metb, 1982, $198,607-609$

54 K.R. Padmanabhan, J. Chevallier and G. Sorenson, J. Mater. Sci. Lett, $1986,5,659-661$

55 C.R. Wie, C.R Shi, M.H. Mendenhall, R.P. Livi, T. Vreeland and T.A. Tombrello, Nucl. Instr. and Metb., 1985, B9, 20-24

56 E.P. EerNisse, J. Appl. Pbys., 1974, 45, 167-174

57 D.K. Sood, W.M. Skinner and J.S. Williams, Nucl. Instr. Metb., 1985, B718, 893-899

58 I.V. Mitchell, J.S. Williams, P. Smith and R.G. Elliman, Appl. Pbys, Lett., 1984, 44, 193-195

59 H. Dallaporta and A. Cros, Appl. Pbys. Lett., 1986, 48, 1357-1359

60 S. Thomas, J. Appl Phys., 1974, 45, 161-166

61 E. Zilinskas, H. Skorobogatas, L. Pranevicious and A. Sakalas, Surface Sci. $1983,134,464-468$ 